\title{
Can a self-administered questionnaire identify workers with chronic or recurring low back pain?
}

\author{
Karina Satiko TAKEKAWA ${ }^{\mathbf{1}}$, Josiane Sotrate GONÇALVES ${ }^{\mathbf{1}}$, \\ Cristiane Shinohara MORIGUCHI ${ }^{1}$, Helenice Jane Cote Gil COURY ${ }^{1}$, \\ and Tatiana de Oliveira SATO ${ }^{1 *}$
}

\footnotetext{
${ }^{1}$ Laboratory of Preventive Physical Therapy and Ergonomics (LAFIPE), Physical Therapy Post Graduate Program, Federal University of São Carlos, Brazil
}

Received November 14, 2014 and accepted March 5, 2015

Published online in J-STAGE March 26, 2015

\begin{abstract}
To verify if the Nordic Musculoskeletal Questionnaire (NMQ), Visual Analogue Scale (VAS), Roland-Morris Disability Questionnaire (RDQ) and physical examination of the lumbar spine can identify workers with chronic or recurring low back pain, using health history for reference. Fifty office workers of both sexes, aged between 19 and $55 \mathrm{yr}$, were evaluated using a standardized physical examination and the NMQ, VAS and RDQ. Discriminant analysis was performed to determine the discriminant properties of these instruments. A higher success rate $(94 \%)$ was observed in the model including only the NMQ and in the model including the NMQ and the physical examination. The lowest success rate $(82 \%)$ was observed in the model including the NMQ, RDQ and VAS. The NMQ was able to detect subjects with chronic or recurring low back pain with $100 \%$ sensitivity and $88 \%$ specificity. The NMQ appears to be the best instrument for identifying subjects with chronic or recurring low back pain. Thus, this self-reported questionnaire is suitable for screening workers for chronic or recurring low back pain in occupational settings.
\end{abstract}

Key words: Health surveillance, Screening, Self-reported tools, Office workers

\section{Introduction}

Low back pain is recurrent in 24 to $33 \%$ of cases, and recurrence can affect the patient's prognosis ${ }^{1)}$. Thus, the commonly used temporal definitions of acute, subacute and chronic low back pain have been questioned, and recurrence is considered an important aspect to consider in this disorder.

The literature appears to lack data regarding the sensitivity and specificity of physical examination and provocative manoeuvres for low back pain. However, the findings

*To whom correspondence should be addressed.

E-mail: karinasatiko@hotmail.com

(C)2015 National Institute of Occupational Safety and Health from a physical examination combined with a detailed health history can facilitate differential diagnosis and treatment management. Nevertheless, in a prospective study involving 295 individuals who had consulted a low back pain specialist, $40 \%$ of the examinations did not involve inspection of the column, and $20 \%$ did not rely on spine palpation ${ }^{2)}$.

Fritz et al. ${ }^{3)}$ conducted a randomized trial in 78 patients with work-related low back pain, and reported that the patients who received treatment based on the findings of a physical examination had better outcomes than the patients who received interventions that did not account for these findings.

Although low back assessments have been extensively studied in these patients, the associations between the 
severity of the condition and functional capacity appears to be weak and conflicting, which can be attributed to the inclusion of people of different ages and clinical statuses ${ }^{4)}$.

In the occupational environment, the evaluation of musculoskeletal disorders is commonly performed through self-reported questionnaires due to their practicability and low $\operatorname{cost}^{5-9)}$.

There is strong evidence that the most consistent predictor of episodes of low back pain and absenteeism is a history of pain ${ }^{9}$. According to Descatha et al. ${ }^{10)}$, the low back history is the benchmark for evaluating this disorder. However, in organizational settings, such as large companies, it is not feasible to perform individualized assessments of all workers on the basis of low back history. In this context, health practitioners need sensible screening tools to identify workers with chronic or recurring low back pain in order to propose specific interventions. The chronicity of pain may be associated with the presence of symptoms below the knee, psychological stress or depression, kinesiophobia, low expectation of recovery, high pain intensity and passive coping style $\mathrm{e}^{1,11)}$.

Thus, the aim of this study was to verify if the Nordic Musculoskeletal Questionnaire (NMQ), Visual Analogue Scale (VAS), Roland-Morris Disability Questionnaire (RDQ) and physical examination of the lumbar spine can distinguish workers with chronic or recurring low back pain, using health history for reference.

\section{Methods}

\section{Subjects}

The workers from an administrative department of a public university were invited to take part in the study by a lecture regarding work-related musculoskeletal disorders prevention and ergonomics. All workers $(\mathrm{N}=142)$ participated in this lecture and 106 agreed to participate by signing the informed consent. An email was sent to the workers that did not sign the consent form in order to reinforce the importance of their participation. However, due to time constraints, fifty workers $(47 \%)$ were evaluated between January and April 2014. The workers who agreed to participate signed an informed consent form. The study was approved by the University's Human Research Ethics Committee (CAAE 0032.0.135.000-07).

The workers were classified into one of two groups according to the report of their history of low back pain: (1) low back pain group (LBP), for those with a history of back pain or (2) control group (CG), for those who did not have a history of low back pain.

\section{Equipment and instruments}

Physical evaluation

The physical evaluation comprised mobility and strength tests, palpation and neurological tests for the lumbar spine. Each item was classified as normal or impaired ${ }^{12,13}$. Mobility was assessed by lumbar range of motion and pain during trunk motion (flexion, extension and lateral bending). The strength of the quadriceps (nerve roots L2, L3 and L4), tibialis anterior (L4 nerve root), extensor hallucis longus (L5 nerve root) and peroneus longus ( $\mathrm{S} 1$ nerve root) was assessed from the midrange of motion of each muscle (12). Palpation was evaluated on the paraspinal muscles, spinous and transverse vertebrae processes (1). Lasègue (sciatic nerve), Straight Leg Raising (SLR) with inversion and dorsiflexion (sural nerve) and with eversion and plantar flexion (tibial nerve) were also tested ${ }^{13)}$.

\section{Nordic Musculoskeletal Questionnaire (NMQ)}

The NMQ was developed to identify musculoskeletal problems in different parts of the body, with questions about the presence of symptoms (pain, tingling and numbness) in the past 12 months and $7 \mathrm{~d}$, functional limitation at home and work and consultation with a health professional due to these symptoms ${ }^{8)}$.

\section{Roland-Morris Disability Questionnaire (RDQ)}

The RDQ is a questionnaire that measures disability due to low back pain. The RDQ was derived from the Sickness Impact Profile (SIP), which is a 136-item questionnaire that generates a measure of health status covering all aspects of physical and mental functions. Roland and Morris selected 24 SIP items relating to physical functions impaired by low back pain. Each item begins with the phrase 'because of my back pain... ${ }^{14)}$.

\section{Visual Analogue Scale (VAS)}

The VAS is a pain scale ranging from 'no pain' to 'worst possible pain'. As this scale shows good correlation with other pain scales, such as the numerical scale, it is easy to understand and apply ${ }^{15,16)}$.

\section{Procedures}

First, the subjects attended a clinical interview that included questions about general musculoskeletal symptoms and pain characteristics to identify the history of low back pain and to classify the subjects into groups (LBP and CG). Next, the subjects answered the NMQ, RDQ and VAS. A physical assessment of the lumbar spine was performed in sequence. 


\section{Data analysis}

The data from the questionnaires and physical assessments were coded. Each positive answer on the NMQ regarding the lower back was assigned 1 point (range from 0 to 4 points); each positive item on the RDQ was assigned 1 point (range from 0 to 24 points); the VAS was considered a continuous variable, ranging from 0 to $100 \mathrm{~mm}$. For the physical examination, each positive item also received 1 point, regardless of whether the involvement was unilateral or bilateral.

The analysis was performed using SPSS 17.0 software, with a significance level of 0.05 . Discriminant analysis (DA) was applied to determine which independent variables (NMQ, VAS, RDQ and physical assessment) would better detect subjects with chronic or recurring low back pain defined by health history. This analysis provided a discriminant function allowing us to determine the probability of belonging to each group ${ }^{17)}$. The DA also provided an index of the importance of each variable: the discriminant coefficients. These coefficients provided quantitative information on the contribution of each variable to the discrimination between groups, making them analogous to standardized regression coefficients (beta) in multiple regression analysis.

Four models were tested to identify the variables that could classify the study population: Model 1 considered the sum of each evaluation method (NMQ, RDQ, VAS and physical examination); Model 2 included the NMQ and physical examination items; Model 3 included the NMQ, RDQ and VAS; and Model 4 included only the NMQ items. Models were chosen by selecting only the plausible combinations of the instruments and the physical examination variables, i.e., combinations which have a practical meaning. Thus Model 1 represented the complete model, Model 2 separated the NMQ in items, Model 3 included only the questionnaires and Model 4 included only the NMQ items.

\section{Results}

The sample comprised 28 individuals with a history of low back pain ( $\mathrm{LBP}=9$ men and 19 women) and 22 workers without a history of pain ( $\mathrm{CG}=9$ men and 13 women). The mean age of the subjects was $32 \mathrm{yr}[\mathrm{LBP}=32.2$ (11.9) and $\mathrm{CG}=32.1$ (3.4) $\mathrm{yr}]$. The average weight of the subjects was $71.0(3.0) \mathrm{kg}$ for the LBP and $65.5(2.8) \mathrm{kg}$ for the CG. The average height was $1.71(0.3) \mathrm{m}$ for the LBP and $1.67(0.1) \mathrm{m}$ for the CG. There was no difference between the groups with regard to these variables.

Figure 1 shows the frequency of positive responses

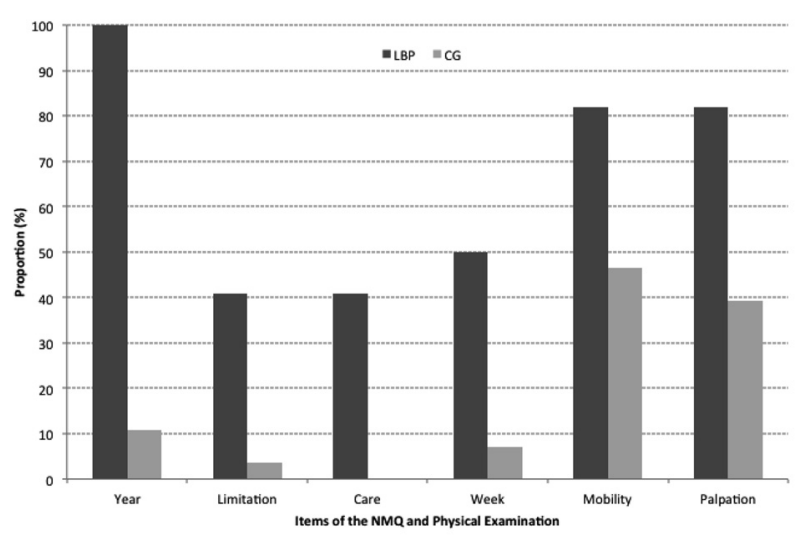

Fig. 1. Proportion of positive responses on the Nordic Musculoskeletal Questionnaire (NMQ) and physical examination for the low back pain (LBP) group and control group (CG).

Year: presence of symptoms in the last 12 months; Limitation: functional limitation to perform work, domestic and leisure activities due to back pain; Care: seeking health care due to low back pain; Week: symptoms in the last $7 \mathrm{~d}$; Mobility: deficit of spinal mobility or pain during movement; Palpation: pain during palpation.

for each item on the NMQ and the physical examination for both groups. The LBP presents a higher proportion of symptoms and findings in the physical assessment as compared to the $\mathrm{CG}$, as expected.

Figure 2 shows the frequency of positive responses on the RDQ according to the groups. Most subjects in both groups reported no positive answers on the RDQ (53\% of the CG and $37 \%$ of the LBP). The number of positive responses in the CG ranged from 1 to 4 , while those in the LBP ranged from 1 to 7 questions.

\section{Discriminant analysis}

Model 1: NMQ, RDQ, VAS and physical assessment

The level of association between the variables was poor, indicating that all variables have discriminant potential. The difference between the means of the two groups was 0.39 $(p \leq 0.01)$ for the NMQ; $0.78(p \leq 0.01)$ for the physical assessment; $0.94(p=0.08)$ for the RDQ and $1.00(p=0.92)$ for the VAS. There was a significant difference between the groups in terms of the NMQ and physical assessment; there was no difference between the groups for the RDQ and VAS.

The discriminant coefficients generated in Model 1 were 0.92 for the NMQ and 0.41 for the physical assessment. The discriminant function was $\mathrm{Z}=1.07 \mathrm{X}+0.22 \mathrm{Y}-1.74$, with $\mathrm{Z}$ being the score reflecting the categorization of individuals into the groups, $\mathrm{X}$ the NMQ score and $\mathrm{Y}$ the physical examination score. The limit values for assignment to the groups (centroids) were 1.50 for the LBP and -1.18 for the CG. 


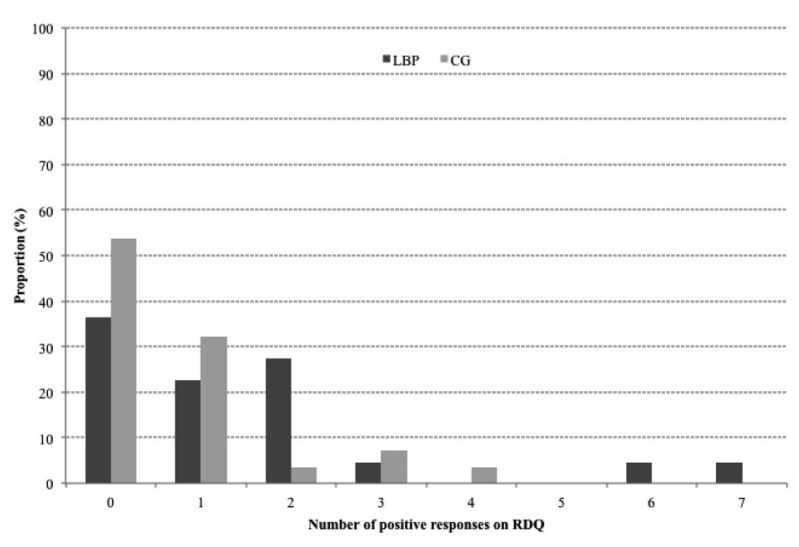

Fig. 2. Percentage of positive responses on the Roland Disability Questionnaire (RDQ) for the low back pain (LBP) group and control group (CG).

The classification of the subjects according to Model 1 showed $88 \%$ correct classification. Six subjects were misclassified: 3 symptomatic workers $(6 \%)$ were classified as asymptomatic (false negative) and 3 asymptomatic workers $(6 \%)$ were classified as symptomatic (false positive).

Model 2: NMQ and physical examination

The association between variables was poor, except for functional limitation and seeking care due to lower back symptoms. The difference between the means of the two groups was $0.21(p \leq 0.01)$ for pain in the past 12 months, $0.78(p \leq 0.01)$ for functional limitation, $0.72(p \leq 0.01)$ for seeking care, $0.76(p \leq 0.01)$ for pain in the past $7 \mathrm{~d}, 0.93$ ( $p=0.06$ ) for mobility and $0.76(p \leq 0.01)$ for palpation.

The discriminant coefficients were 0.91 for pain in the past 12 months, 0.32 for seeking care and 0.34 for palpation. The reported pain in the last year was the strongest factor discriminating the subjects, followed by palpation and demand for care.

The discriminant function was $\mathrm{Z}=3.87 \mathrm{~A}+0.97 \mathrm{M}+0.27 \mathrm{P}$ -2.44 , with $\mathrm{Z}$ being the classification of each subject, $\mathrm{A}$ the pain in the past 12 months, $\mathrm{M}$ the demand for care and $\mathrm{P}$ the palpation score. The centroids were 2.37 for the LBP and -1.86 for the CG. The final classification showed 3 asymptomatic individuals classified as symptomatic (false positive) and $94 \%$ of the original cases correctly classified.

\section{Model 3: NMQ, RDQ and VAS}

The level of association between variables was poor. The difference between the group means was $0.39(p \leq 0.01)$ for the NMQ, $0.94(p=0.08)$ for the RDQ and $1.00(p=0.92)$ for the VAS. Thus, the RDQ and VAS do not distinguish between the groups.
The discriminant function was $Z=1.16 \mathrm{X}-1.33$, with $\mathrm{Z}$ being the final score and $X$ the NMQ score. The centroids were 1.37 for the LBP and -1.08 for the CG. In this model, 9 subjects (18\%) were classified differently from the original classification: 3 asymptomatic and 6 symptomatic.

Model 4: Individual items of the NMQ

The association between variables was poor, except for functional limitation and seeking care, which were strongly associated with each other. The difference between the means was $0.21(p \leq 0.01)$ for symptoms in the past 12 months, 0.78 ( $p \leq 0.01)$ for functional limitation, 0.72 for seeking care $(p \leq 0.01)$ and $0.76(p \leq 0.01)$ for symptoms in the past $7 \mathrm{~d}$. Thus, all items have discriminant potential.

The discriminant coefficients were 0.95 for symptoms in the past 12 months and 0.31 for seeking care. Thus, the other items of the NMQ did not show discriminant potential. The discriminant function was $\mathrm{Z}=4.03 \mathrm{X}+0.93 \mathrm{M}$ -2.18 . The centroids were 2.23 for the LBP and -1.75 for the CG. The final classification resulted in 3 subjects being classified differently from their original classification; thus, there was $94 \%$ correct classification.

Table 1 summarizes the results obtained in the models. Model 4 showed the best cost benefit results, since it included only the results of the NMQ and presented the highest sensitivity and specificity.

\section{Discussion}

The present study aimed to verify if a questionnaire and a physical examination could be used to identify subjects with chronic or recurring low back pain. Fifty office workers from the same workplace and subject to similar working conditions were recruited to participate. The subjects' demographic data were also similar. This helped to reduce individual influences on the results. The DA indicated that the NMQ showed good discrimination capability. The results of the study showed that workers with chronic or recurring low back pain were more restricted in their work, housework and leisure activities, and therefore sought health assistance with higher frequency, as expected ${ }^{18,19)}$.

Since the worker's low back health history, questionnaire responses and physical examination were based on his or her perception, this may have compromised the outcome validity. However, there are no other tests available to confirm the anatomical source of back pain, and thus provide an accurate diagnosis. Moreover, the consensus is that these exams have variable rates of false positive and negative ${ }^{1)}$, and the use of these tests has also been questioned. 
Table 1. Final classification obtained in each model, success rate, sensitivity and specificity

\begin{tabular}{|c|c|c|c|c|c|c|c|}
\hline \multirow{2}{*}{ Models } & \multirow{2}{*}{ Groups } & \multicolumn{2}{|c|}{ Final classification } & \multirow{2}{*}{ Total } & \multirow{2}{*}{ Success rate } & \multirow{2}{*}{ Sensitivity } & \multirow{2}{*}{ Specificity } \\
\hline & & CG & LBPG & & & & \\
\hline \multirow[t]{2}{*}{ 1. NMQ, RDQ, VAS and PE } & $\mathrm{CG}$ & 25 & 3 & 28 & $88 \%$ & 0.89 & 0.86 \\
\hline & LBP & 3 & 19 & 22 & & & \\
\hline \multirow[t]{2}{*}{ 2. NMQ and PE } & CG & 25 & 3 & 28 & $94 \%$ & 1.00 & 0.88 \\
\hline & LBP & 0 & 22 & 22 & & & \\
\hline \multirow[t]{2}{*}{ 3. NMQ, RDQ and VAS } & $\mathrm{CG}$ & 25 & 3 & 28 & $82 \%$ & 0.81 & 0.84 \\
\hline & LBP & 6 & 16 & 22 & & & \\
\hline \multirow[t]{2}{*}{ 4. NMQ } & CG & 25 & 3 & 28 & $94 \%$ & 1.00 & 0.88 \\
\hline & LBP & 0 & 22 & 22 & & & \\
\hline
\end{tabular}

NMQ: Nordic Musculoskeletal Questionnaire; RDQ: Roland Disability Questionnaire; VAS: Visual Analogue Scale; PE: physical examination; CG: control group; LBP: low back pain group

Sensitivity is the ability of a test to correctly classify a symptomatic individual, whereas specificity is the property that a test has to correctly classify a healthy individual, and the closer these values are to $100 \%$, the more accurate the test is ${ }^{20)}$. Considering this, Model 4 showed the best results; thus, the NMQ showed a high ability to identify a worker with chronic or recurring low back pain and $22 \%$ likelihood of a false positive.

In this study, the acute and subacute low back pain workers were classified as asymptomatic (CG). Thus, the false positive rate may have been due to the fact that the NMQ did not differentiate between types of back pain. It is likely that some individuals in the CG who had had acute and subacute pain in the previous year responded positively to questions on the NMQ. Nevertheless, the NMQ showed a greater potential than the other instruments to identify workers with chronic or recurring low back pain. This result indicates that the NMQ, although not structured to assess chronic and recurring pain, was more sensitive to evaluating these types of pain; thus, this tool could be used to predict future episodes of low back pain. However, the high sensitivity of this instrument is important in the occupational setting, as it could be used for screening workers, and the false positive would yield less relevant consequences than a false negative would, in relation to the implementation of specific actions in companies.

The most important items on the NMQ for discriminating between groups were the presence of pain in the last year and seeking health care, suggesting that these questions are closely related to chronic or recurring low back pain.

In Model 2, which included the NMQ and physical assessment, the discriminant variables were also the two questions of the NMQ and palpation. These results are consistent with studies showing that symptomatic indi- viduals have greater pain sensitivity in the lumbar spine and seek health assistance more often ${ }^{12,21)}$.

In addition, office workers spend much of their time in static postures that require low mobility and continuous activation of the trunk muscles. Therefore, both groups are subject to activities with similar muscular demands ${ }^{22}$. These factors may explain why the VAS failed to discriminate between the groups.

The RDQ did not discriminate the groups. This result can be explained by the low level of disability in the sample, since the highest score was 7 points ${ }^{1,14)}$. The RDQ and VAS were not sensitive, so these tools should not be used for screening for low back pain in the occupational context; nevertheless, this does not diminish their importance in the clinical evaluation of patients ${ }^{23-25}$.

Although all models showed acceptable sensitivity and specificity, Models 2 and 4 yielded better results ${ }^{26)}$. Model 4 is the most practical model for screening workers for chronic or recurring low back pain in occupational settings.

\section{Conclusion}

The evaluation of low back pain in the last year and seeking health care on the NMQ identified subjects with chronic or recurring low back pain with sensitivity of $100 \%$ and specificity of $88 \%$. The RDQ and VAS did not distinguish workers with low back pain. Although physical examinations are important in the clinical context, in occupational settings, they did not increase sensitivity and specificity.

\section{References}

1) Delitto A, George SZ, Van Dillen LR, Whitman JM, Sowa G, Shekelle P, Denninger TR, Godges JJ, Orthopaedic Section 
of the American Physical Therapy Association (2012) Low back pain. J Orthop Sports Phys Ther 42, A1-57. [CrossRef] [Medline]

2) Press J, Liem B, Walega D, Garfin S (2013) Survey of inspection and palpation rates among spine providers: evaluation of physician performance of the physical examination for patients with low back pain. Spine $\mathbf{3 8}$, 1779-84 10.1097/BRS.0b013e31829ff32f. [Medline]

3) Fritz JM, Whitman JM, Flynn TW, Wainner RS, Childs JD (2004) Factors related to the inability of individuals with low back pain to improve with a spinal manipulation. Phys Ther 84, 173-90. [Medline]

4) Lyle MA, Manes S, McGuinness M, Ziaei S, Iversen MD (2005) Relationship of physical examination findings and self-reported symptom severity and physical function in patients with degenerative lumbar conditions. Phys Ther 85, 120-33. [Medline]

5) Lee JW, Lee JJ, Mun HJ, Lee KJ, Kim JJ (2013) The relationship between musculoskeletal symptoms and workrelated risk factors in hotel workers. Ann Occup Environ Med 25, 20. [CrossRef] [Medline]

6) Moreira RF, Sato TO, Foltran FA, Silva LC, Coury HJ (2014) Prevalence of musculoskeletal symptoms in hospital nurse technicians and licensed practical nurses: associations with demographic factors. Braz J Phys Ther 18, 323-33. [CrossRef] [Medline]

7) Ng YG, Tamrin SB, Yik WM, Yusoff IS, Mori I (2014) The prevalence of musculoskeletal disorder and association with productivity loss: a preliminary study among labour intensive manual harvesting activities in oil palm plantation. Ind Health 52, 78-85. [CrossRef] [Medline]

8) Pinheiro FA, Troccoli BT, Carvalho CV (2002) Validity of the Nordic Musculoskeletal Questionnaire as morbidity measurement tool. Rev Saude Publica 36, 307-12. [CrossRef] [Medline]

9) Waddell G, Burton AK (2001) Occupational health guidelines for the management of low back pain at work: evidence review. Occup Med (Lond) 51, 124-35. [CrossRef] [Medline]

10) Descatha A, Roquelaure Y, Chastang JF, Evanoff B, Melchior M, Mariot C, Ha C, Imbernon E, Goldberg M, Leclerc A (2007) Validity of Nordic-style questionnaires in the surveillance of upper-limb work-related musculoskeletal disorders. Scand J Work Environ Health 33, 58-65. [CrossRef] [Medline]

11) Beneciuk JM, Bishop MD, Fritz JM, Robinson ME, Asal NR, Nisenzon AN, George SZ (2013) The STarT back screening tool and individual psychological measures: evaluation of prognostic capabilities for low back pain clinical outcomes in outpatient physical therapy settings. Phys Ther 93, 321-33. [CrossRef] [Medline]

12) Golob AL, Wipf JE (2014) Low back pain. Med Clin North Am 98, 405-28. [CrossRef] [Medline]

13) Magee DJ (2013) Orthopedic Physical Assessment, 6th Ed. Elsevier.
14) Nusbaum L, Natour J, Ferraz MB, Goldenberg J (2001) Translation, adaptation and validation of the Roland-Morris questionnaire-Brazil Roland-Morris. Braz J Med Biol Res 34, 203-10. [CrossRef] [Medline]

15) Kelly AM (2001) The minimum clinically significant difference in visual analogue scale pain score does not differ with severity of pain. Emerg Med J 18, 205-7. [CrossRef] [Medline]

16) Haukka E, Leino-Arjas $P$, Ojajärvi A, Takala EP, ViikariJuntura E, Riihimäki H (2011) Mental stress and psychosocial factors at work in relation to multiple-site musculoskeletal pain: a longitudinal study of kitchen workers. Eur J Pain 15, 432-8. [CrossRef] [Medline]

17) Burns R, Burns R (2009) Business Research Methods and Statistics using SPSS. SAGE Publications.

18) Driscoll T, Jacklyn G, Orchard J, Passmore E, Vos T, Freedman G, Lim S, Punnett L (2014) The global burden of occupationally related low back pain: estimates from the Global Burden of Disease 2010 study. Ann Rheum Dis 73, 975-81. [CrossRef] [Medline]

19) Deyo RA, Mirza SK, Martin BI (2006) Back pain prevalence and visit rates: estimates from U.S. national surveys, 2002. Spine 31, 2724-7. [CrossRef] [Medline]

20) Parikh R, Mathai A, Parikh S, Chandra Sekhar G, Thomas R (2008) Understanding and using sensitivity, specificity and predictive values. Indian J Ophthalmol 56, 45-50. [Medline] [CrossRef]

21) Krismer M, van Tulder M, Low Back Pain Group of the Bone and Joint Health Strategies for Europe Project (2007) Strategies for prevention and management of musculoskeletal conditions. Low back pain (non-specific). Best Pract Res Clin Rheumatol 21, 77-91. [CrossRef] [Medline]

22) Mörl F, Bradl I (2013) Lumbar posture and muscular activity while sitting during office work. J Electromyogr Kinesiol 23, 362-8. [CrossRef] [Medline]

23) McGregor AH, Doré CJ, McCarthy ID, Hughes SP (1998) Are subjective clinical findings and objective clinical tests related to the motion characteristics of low back pain subjects? J Orthop Sports Phys Ther 28, 370-7. [CrossRef] [Medline]

24) Scharovsky A, Pueyrredón M, Craig D, Rivas ME, Converso G, Pueyrredón JH, Salvat F, Alzúa O (2008) Cross-cultural adaptation and validation of the Argentinean version of the Roland-Morris Disability Questionnaire. Spine 33, 1391-5. [CrossRef] [Medline]

25) Schinkel-Ivy A, Nairn BC, Drake JD (2013) Investigation of trunk muscle co-contraction and its association with low back pain development during prolonged sitting. J Electromyogr Kinesiol 23, 778-86. [CrossRef] [Medline]

26) Terwee CB, Bot SD, de Boer MR, van der Windt DA, Knol DL, Dekker J, Bouter LM, de Vet HC (2007) Quality criteria were proposed for measurement properties of health status questionnaires. J Clin Epidemiol 60, 34-42. [CrossRef] [Medline] 